\title{
Experimental investigation of water supply pipeline behavior in frozen soil
}

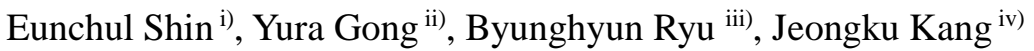 \\ i) Professor, Dean of Urban Science College, Incheon National University, South Korea. \\ ii) MS Student, Dept. of Civil and Environmental Engrg., Incheon National University, South Korea. \\ iii) Senior Researcher, Ph. D., Korea Institute of Construction Technology, South Korea. \\ iv) Research Professor, Urban Science Institute, Incheon National University, South Korea.
}

\begin{abstract}
Water supply pipelines are frequently damaged due to freezing problem every year. In order to reduce the damages resulting from such freezing and thawing cycles, pipelines, especially the water supply pipelines are buried below the depth of soil freezing to prevent the freezing of the roadbed. It was carried out to investigate the behavior of water supply pipeline laid underground in the winter season through a multi layered field model test. The ductile steel pipe and stainless pipe were used as the water supply pipe lines. The field experimental work was performed in the 3 different soil ground conditions. The strains on the water supply pipelines were measured in the field for both stainless pipe and ductile steel pipe. The results of field measured strain were compared with the results of simulated numerically strain. Based on the experimental test results, the contents of fine grained soil and degree of saturation as well as the soil temperature below zero are greatly influenced on the earth pressure on the water supply pipeline. The magnitude of earth pressure increases approximately in the range of 2.4 3.7 times with the variations of temperatures from $0{ }^{\circ} \mathrm{C}$ to $-10^{\circ} \mathrm{C}$. In the case of estimation of the total pressure applied over the water supply pipeline should be considered not only earth pressure by Marston and Spangler's theory but also freezing pressure induced by the ground freezing.
\end{abstract}

Keywords: freezing and thawing, freezing index, freezing depth, ductile steel pipe line, frost heaving

\section{INTRODUCTION}

The Korean Peninsula is geographically situated in the northern latitude of $33^{\circ} \sim 43^{\circ}$. The annual average temperature of the Seoul metropolitan area in January for 20 years ranges from $-6^{\circ} \mathrm{C}$ to $+7^{\circ} \mathrm{C}$ with the annual precipitation of $1400 \mathrm{~mm}$. The coldest temperature in January sometimes goes down from $-15^{\circ} \mathrm{C}$ to $-18^{\circ} \mathrm{C}$. During the winter season, the climate is heavily influenced by the Siberian continental air pressure. The cold Siberian air mass during winter induces frost heaving by freezing the moisture of soils, therefore increasing of potential damages of social infrastructures such as water supply pipelines, roadways, railways, and retaining walls.

Water supply pipelines are frequently damaged due to freezing problem every year. Furthermore, the number of pipeline failures is expected to increase significantly due to abnormal climate changes from recent global warming. The average numbers of breakage for water supply pipeline (WSP) are steadily increased with the influence of climate changes. Damages to structures occur quite extensively from repetition of freezing and thawing of roads, railways, and buried pipelines over winter to spring seasons. In order to reduce the damages resulting from seasonal reasons, the water supply pipelines are buried below the depth of soil freezing to prevent the freezing of the roadbed. However, ruptures from freezing of the water supply pipelines still continually occur every winter. Freezing depth of South Korea shows in Fig. 1.

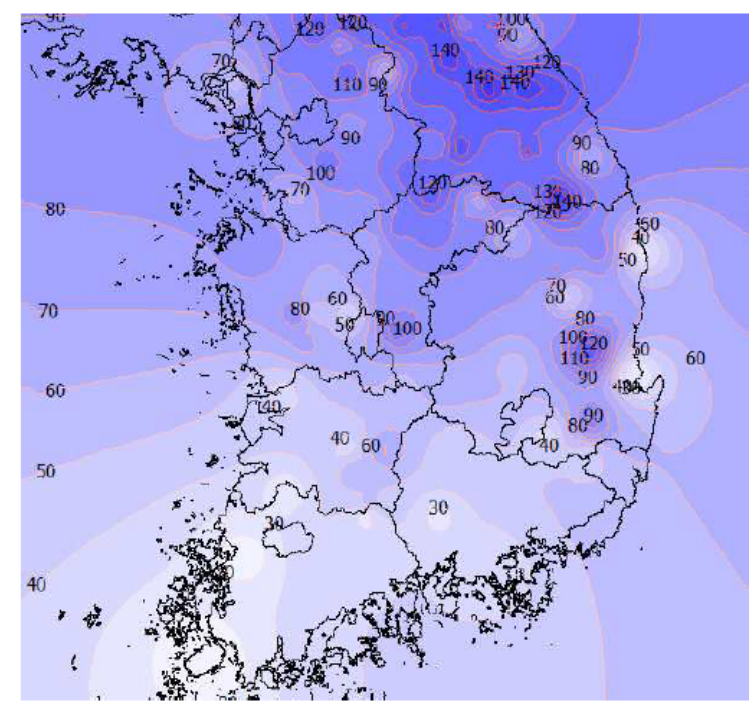

Fig. 1. Maximum freezing depth of South Korea (2014). 
In the year 2011 alone, the Ministry of Environment reported that more than 1000 gauges of drinking water supply pipelines was damaged in the Seoul metropolitan. Particularly the number of breakage for WSP was rapidly increased up to 2652 due to severe low temperature in the northern part of the Korean Peninsula. As a results, substantial portion of the national budget is used in the restoration of water supply facilities. Table 1 gives the numbers of breakage of WSP with the annual average winter season temperature.

Table 1. Annual breakage of WSP and temperature in Seoul metropolitan area.

\begin{tabular}{c|c|c|c|c|c}
\hline Year & '06 & '07 & '08 & '09 & '10 \\
\hline $\begin{array}{c}\text { Number } \\
\text { of breakage }\end{array}$ & 391 & 220 & 404 & 451 & 2652 \\
\hline $\begin{array}{c}\text { Average } \\
\text { winter } \\
\text { temperature } \\
\left({ }^{\circ} \mathrm{C}\right)\end{array}$ & -1.47 & 1.47 & 0.53 & 0.23 & -1.23 \\
\hline
\end{tabular}

The freezing pressure induced by temperature is a major cause of breakage for WSP which buried in underground during winter season.

However, numbers of other factors are influenced on the damage of WSP such as composition material of pipe itself, chemical components of water, bedding material and surrounding soils and maximum water pressure inside the pipeline as well as traffic load from the ground surface (Park et al., 2008). The factors and items to influence on the damage of WSP are tabulated in Table 2.

Table 2. Factors and items related to damage of WSP.

\begin{tabular}{l|l}
\hline \multicolumn{1}{c|}{ Factors } & \multicolumn{1}{c}{ Items } \\
\hline Material of pipe & PCP, PVC, PE, stainless steel \\
\hline Internal decay & pH, density of hydrogen sulfide \\
\hline $\begin{array}{l}\text { External decay } \\
\begin{array}{l}\text { Surcharged lead to } \\
\text { outer of pipe and } \\
\text { internal load }\end{array}\end{array}$ & $\begin{array}{l}\text { Type of soil, electric resistivity of } \\
\text { soil, frost sensitivity of soil } \\
\text { region, traffic load }\end{array}$ \\
\hline $\begin{array}{l}\text { Construction related } \\
\text { factors }\end{array}$ & $\begin{array}{l}\text { Bedding material for installation of } \\
\text { pipe. Diameter off pipe } \\
\text { (D } \leq 100 \mathrm{~mm}, \mathrm{D} \geq 700 \mathrm{~mm})\end{array}$ \\
\hline
\end{tabular}

\section{THEORIES OF WATER SUPPLY PIPELINE}

The external loads applied on the top of the WSP are static load by the overburden soil above the pipeline and surcharged load on the ground surface, dynamic load due to the ground traffic load or unknown dynamic load, and water pressure inside WSP. The additional external load can be applied by the soil freezing pressure during the cold winter season.

Marston and Anderson (1913) studied about the theory of loads on pipes and ditches under the condition of soil filling above the WSP and also proposed the theory of earth pressure with backfilling of soil in the braced cut for installation of WSP. Earth pressures applied on WSP is shown in Fig 2.

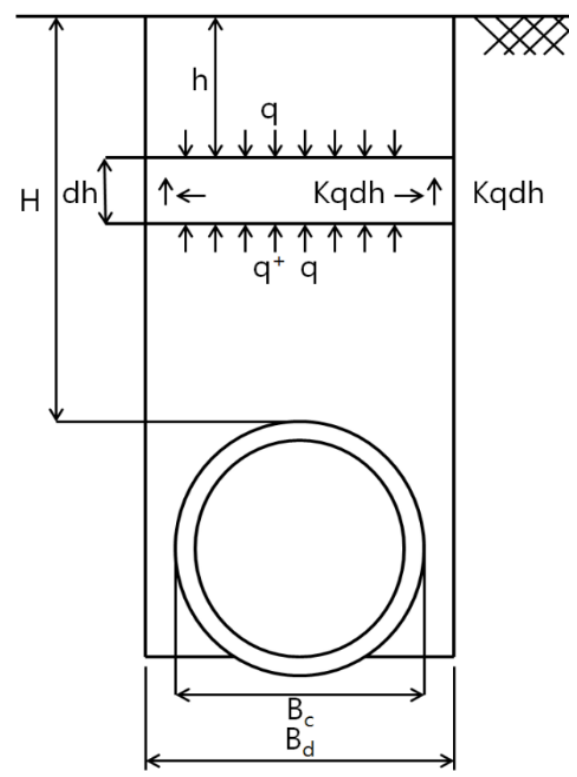

Fig. 2. Earth pressures applied on the underground WSP.

From the schematic diagram of Fig. 2, Marston and Spangler suggested the equilibrium of forces which applied both top and bottom of WSP for a unit length as follows (Spangler and Handy, 1982),

$$
q B_{d}+d q B_{d}+2 \mu K q d h=q B_{d}+\gamma B_{d} d h
$$

Where, $q B_{d}$ is the downward vertical force which applied to the top of the WSP, and $q B_{d}+d q B_{d}$ is the upward vertical force. The term of $\gamma B_{d} d h$ is the weight of WSP in the downward direction and Kqdh is the horizontal force which applied at the side of WSP, and $\mu K q d h$ is the upward frictional force for both sides of WSP. Eq. (1) can be rearranged as Eq. (2),

$$
d q B_{d}+2 \mu K q d h=\gamma B_{d} d h
$$

Let's divide Eq. (2) by $B_{d}$ and $d h$ for both side, the linear differential equation can be obtained as 


$$
\frac{d q}{d h}+\frac{2 K \mu}{B d} q=\gamma
$$

Meanwhile, as the solution of a linear equation of $y^{\prime}=f(x) y=r(x)$ is $y=e^{-k}\left[\int e^{k} r d x+c\right]$ and $k=\int f(x) d x$, the vertical pressure on the WSP can be derived as follows,

$$
\begin{gathered}
k=\int \frac{2 K \mu}{B_{d}} d h \\
q=e^{-\frac{2 K \mu}{B_{d}}}\left[\frac{B_{d}}{2 K \mu} e^{\frac{2 K \mu}{B_{d}}} r+C\right]
\end{gathered}
$$

By integration of Eq. (5) with respect to the boundary conditions $\mathrm{h}=0, \mathrm{q}=0$ for determination of $\mathrm{C}$. So, the vertical applied pressure $\mathrm{q}$ is expressed as

$$
q=\frac{\gamma B_{d}}{2 K \mu}\left[1-e^{-\frac{2 K \mu_{h}}{B_{d}}}\right]
$$

Substitute $\mathrm{H}$ of Figure 2 for $\mathrm{h}$ for determination of vertical pressure on WSP,

Let the angle of soil friction, $C_{d}=\frac{1-e^{-\frac{2 K \mu}{B_{d}} H}}{2 K \mu}$ and substitute to Eq. (6),

$$
q=C_{d} \gamma B_{d}
$$

Then,

$$
W_{c}=C_{d} \gamma B_{d}^{2}
$$

Where, $W_{c}$ is the total dead load applied in the top of WSP for a unit length $\gamma$ is the unit weight of backfill soil, and $B_{d}$ is the width of excavated trench.

\section{EXPERIMENTAL FIELD TEST OF WSP}

Field experimental study was conducted on the campus of Incheon National University to evaluate the behavior of buried WSP under the various test conditions such as soil conditions, material type of WSP, content of unfrozen water, and temperature in the air. The lowest temperature at this site is $-12^{\circ} \mathrm{C}$ and the duration of below zero temperature is about 80 days per year.

A large size metal model box was fabricated with a size of $3 \mathrm{~m}$ (width) $\times 6 \mathrm{~m}$ (length) $\times 3 \mathrm{~m}$ (height). The longitudinal section is divided into 3 and thus 3 test sections are established for field experimental work. The test pit for WSP was prepared in the university with the experimental box of which the installation sequence is shown in Fig. 3.

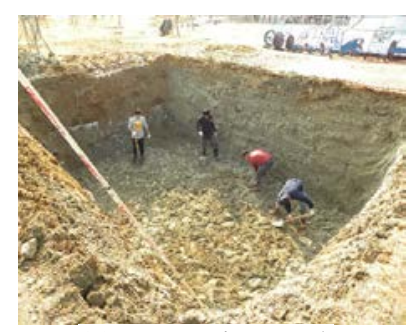

(a) Excavation work

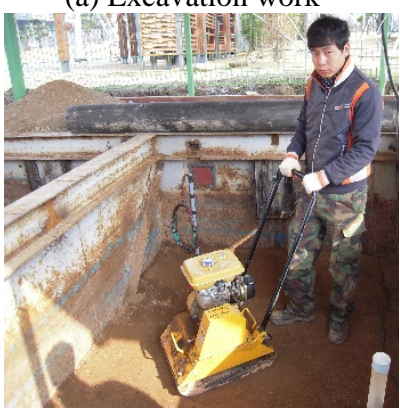

(c) Soil compaction

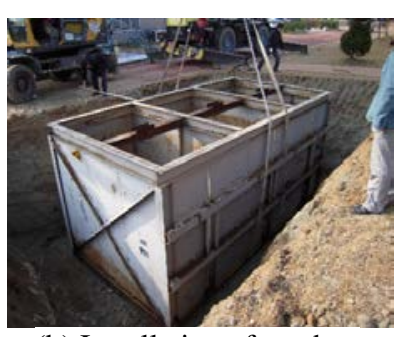

(b) Installation of test box

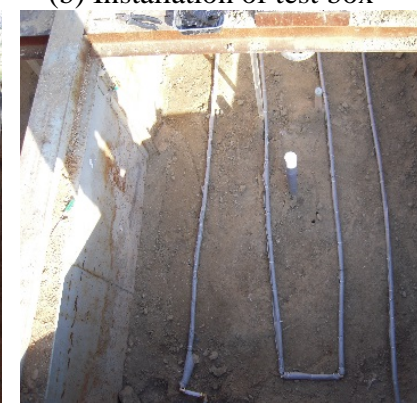

(d) Ground water system
Fig. 3. Preparation sequences of field test pit for WSP.

The underground temperature, frozen depth, layered settlement, and ground level settlement were measured by using relevant devices. It was installed the instrumentation of monitoring devices as well as the types of soil at each soil layer. The cross-sections for each test model is shown in Fig. 4.

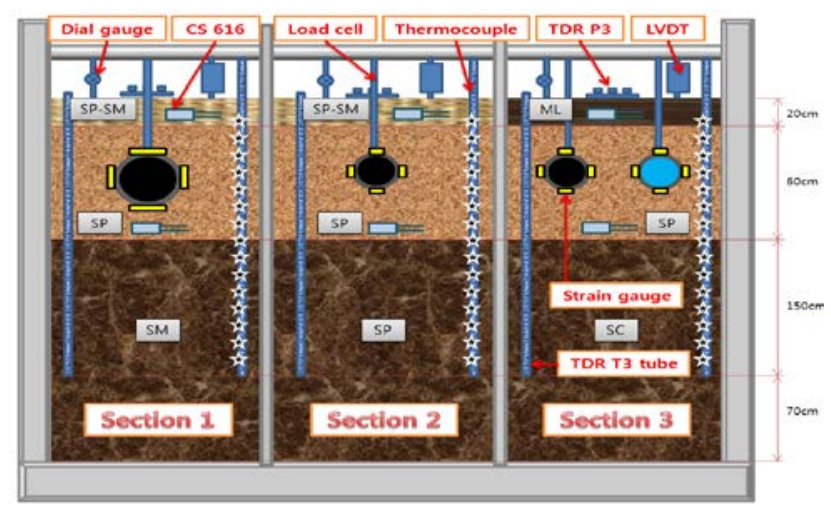

Fig. 4. Schematic diagram of field experimental work for WSP with various monitoring instruments.

The ductile metal WSP with a diameter of $200 \mathrm{~mm}$ was buried at the depth of $50 \mathrm{~cm}$ from the ground level for test Section-1. The foundation soil was filled at the bottom $70 \mathrm{~cm}$ and $150 \mathrm{~cm}$ thick SM soil was formed at the layer 3 , and then $60 \mathrm{~cm}$ thick SP soil at the layer 2 was formed with an appropriate compaction effort. Final cover soil with $20 \mathrm{~cm}$ thickness was formed by using a decomposed granite soil.

The stainless steel WSP with a diameter of $50 \mathrm{~mm}$ was installed for the test Section-2 and Section-3 and the soil conditions are varied with the silty clayey soil (ML) for the cover soil for Section-3, but the top soil cover (SP-SW) for test Section-2 is the same as in test Section-1 for the purpose of comparison of WSP behavior. 
All detail soil properties for each test section and layers are described in Table 3.

Table 3. Physical properties of each layered soil for each field test section.

\begin{tabular}{|c|c|c|c|c|c|c|c|}
\hline Situation & $\begin{array}{l}\text { S1, } \\
\text { S2, } \\
\text { L1 }\end{array}$ & $\begin{array}{l}\text { S3, } \\
\text { L1 }\end{array}$ & $\begin{array}{l}\text { S1, } \\
\text { S2, } \\
\text { L2 }\end{array}$ & $\begin{array}{l}\text { S3, } \\
\text { L2 }\end{array}$ & $\begin{array}{l}\text { S1, } \\
\text { L3 }\end{array}$ & $\begin{array}{l}\text { S2, } \\
\text { L3 }\end{array}$ & $\begin{array}{l}\text { S3, } \\
\text { L3 }\end{array}$ \\
\hline $\begin{array}{c}\text { Specific } \\
\text { gravity } \\
\left(G_{s}\right)\end{array}$ & 2.62 & 2.73 & 2.63 & 2.66 & 2.67 & 2.63 & 2.66 \\
\hline $\begin{array}{c}0.074 \mathrm{~mm} \\
\text { passing } \\
(\%)\end{array}$ & 11.7 & 58.9 & 1.9 & 2.3 & 19.6 & 1.9 & 22.7 \\
\hline $\begin{array}{c}\gamma_{d} \\
\left(\mathrm{kN} / \mathrm{m}^{3}\right)\end{array}$ & 19.6 & 14.0 & 18.8 & 19.5 & 18.9 & 18.8 & 17.8 \\
\hline $\begin{array}{l}w_{o p t} \\
(\%)\end{array}$ & 10.5 & 27.4 & 11.5 & 10.5 & 12.4 & 11.5 & 16.5 \\
\hline $\begin{array}{c}\text { Coefficie } \\
\text { nt of } \\
\text { Uniformit } \\
y \\
(\mathrm{Cu})\end{array}$ & 44.3 & 32.6 & 3.05 & 9.25 & 34.6 & 3.05 & 10.0 \\
\hline $\begin{array}{l}\text { Coefficie } \\
\text { nt of } \\
\text { gradation } \\
\text { (Cc) }\end{array}$ & 2.30 & 1.68 & 1.69 & 0.61 & 4.63 & 1.69 & 1.23 \\
\hline USCS & $\begin{array}{l}\text { SP- } \\
\text { SW }\end{array}$ & ML & SP & $\begin{array}{l}\text { SP } \\
(2)\end{array}$ & SM & SP & SC \\
\hline
\end{tabular}

\section{EXPERIMENTAL TEST RESULTOF WSP}

The frost heaving of soil ground occurs when the water supplies into the soil ground continuously under the temperature below $0^{\circ} \mathrm{C}$. The variation of air temperatures at the experimental site were measured as shown in Fig. 5. The temperature was measured mostly below $0^{\circ} \mathrm{C}$ for 81days from December 3, 2012 to February 21, 2013.

The freezing index was approximately $226^{\circ} \mathrm{C}$ day at this particular site in Incheon, Korea. The soil temperature were measured with respect to the depth of soil at every $10 \mathrm{~cm}$ interval for 3 test sections. The magnitudes of heave amount with the corresponding freezing depth for the year 2012-2013 winter seasons are shown in Fig 6.

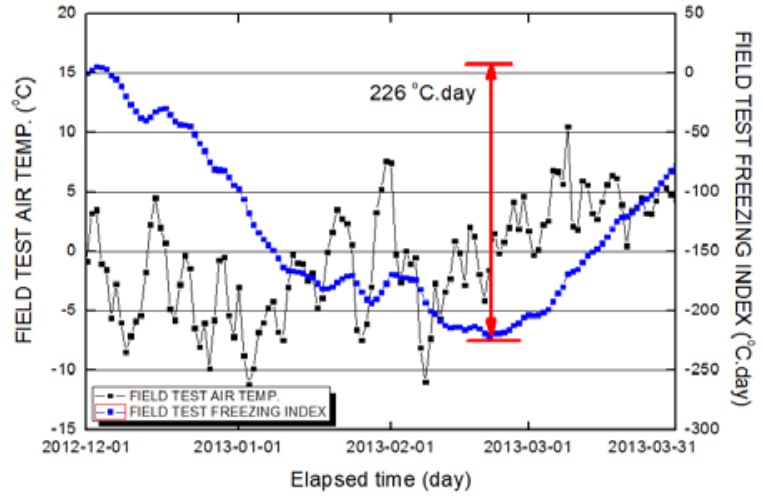

Fig. 5. Variation of air temperature with the freezing index for field test site.

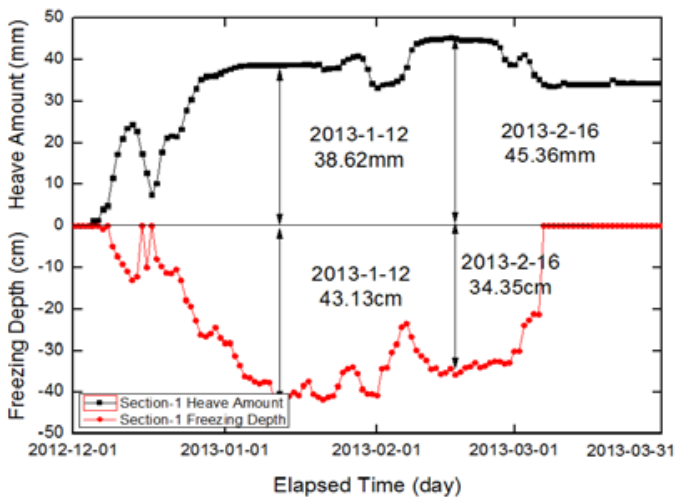

(a) Section-1

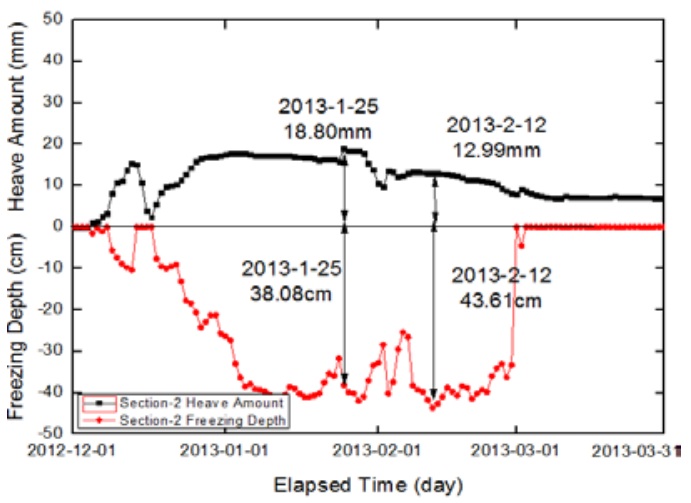

(b) Section-2

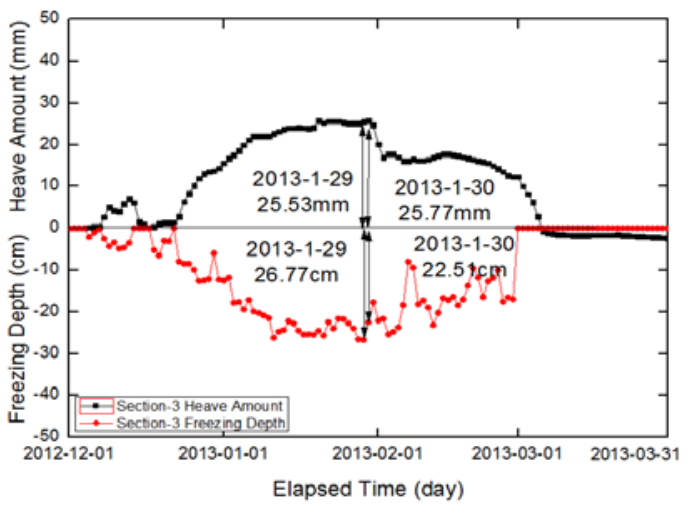

(c) Section-3

Fig. 6. Magnitude of heaving and freezing depth for 3 different test Sections. 
The highest heave amount was occurred under the condition of deepest freezing depth for test Section-1 with comparison of test Section-2, and Section-3, because test Section-1 introduced the underground water into the soil ground. The underground freezing depth gave the freezing pressure to the settlement plate which was installed on the ground surface and at the soil depth of $20 \mathrm{~cm}$, respectively.

So, the settlement plate moved upward direction with soil heaving and also downward direction due to freezing earth pressure. These measurements are tabulated for 3 test sections in Table 4.

Table 4. Magnitude of frost heaving for various ground conditions.

\begin{tabular}{c|c|c|c}
\hline Classification & S1 & S2 & S3 \\
\hline $\begin{array}{c}\text { Heave amount at ground } \\
\text { level (mm) }\end{array}$ & 44.96 & 17.67 & 25.62 \\
\hline $\begin{array}{c}\text { Heave amount } \\
\text { at GL-20cm (mm) }\end{array}$ & -6.09 & -4.94 & -5.54 \\
\hline
\end{tabular}

The strains on the WSP were measured during the freezing period both in the longitudinal direction and in the circumferential directions. As an example of test Section-1, the strain distribution occurs at the upper part of ductile steel pipe is shown in Fig. 7 (a) and strain distribution at the lower part of ductile steel pipe is shown in Fig. 7 (b).

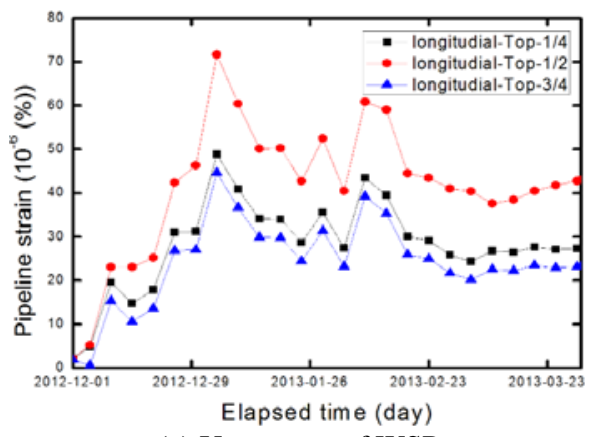

(a) Upper part of WSP

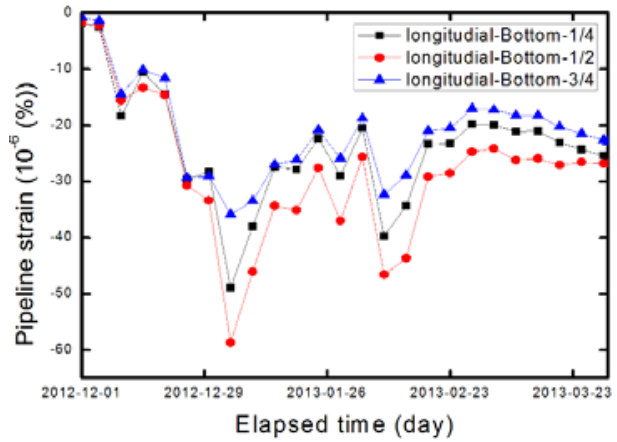

(b) Lower part of WSP

Fig. 7. Strain distribution on the ductile steel pipe for test Section-1.
The result of strain measurement on the WSP are reversely proportional each other for the given dates of measurement. This means that the top of WSP gets the compression stress and the bottom of WSP takes tension stress due to the freezing of soil ground.

The strain data were measured for 3 test sections in longitudinal as well as circumferential directions. The poisson's ratio by laboratory test can be estimated from these results as 0.28 for ductile steel pipe and 0.26 for stainless steel pipe.

The earth pressures applied on the top of WSP were measured for 3 different sections with the elapsed time which is shown in Fig. 8.

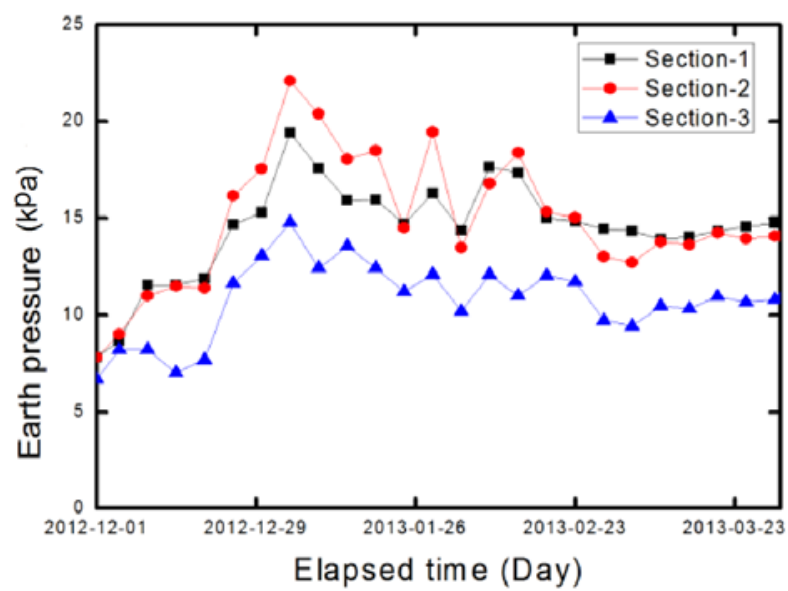

Fig. 8. Earth pressure induced ground freezing with elapsed time.

The earth pressures with respect to the freezing depths are described in Table 5. The depth of maximum earth pressure of S1, S2, and S3 was measured at $43.13 \mathrm{~cm}, 38.08 \mathrm{~cm}$, and $26.77 \mathrm{~cm}$, respectively.

Table 5. Earth pressure induced by freezing at various soil depths.

\begin{tabular}{c|c|c|c}
\hline \multirow{2}{*}{ Frost depth(cm) } & \multicolumn{3}{|c}{ Earth pressure (kPa) } \\
\cline { 2 - 4 } & $\mathrm{S} 1$ & $\mathrm{~S} 2$ & $\mathrm{~S} 3$ \\
\hline \multirow{2}{*}{0} & 7.82 & 7.82 & 6.74 \\
\hline \multirow{2}{*}{20} & 14.677 & 16.15 & 11.65 \\
\hline \multirow{2}{*}{$\begin{array}{c}\text { Maximum earth } \\
\text { pressure }\end{array}$} & 19.4 & 22.1 & 14.78 \\
& $(43.13 \mathrm{~cm})$ & $(38.08 \mathrm{~cm})$ & $(26.77 \mathrm{~cm})$ \\
\hline
\end{tabular}

The comparison of earth pressures under the freezing condition and without freezing condition, that is, Marston's theory in Eq. (8) are made with variations of temperatures. These results are described in Table 6 . 
Table 6. Comparison of field measured earth pressures with Marston's theory.

\begin{tabular}{c|c|c|c|c|c|c}
\hline \multirow{2}{*}{$\begin{array}{c}\text { Temp. } \\
\left({ }^{\circ} \mathrm{C}\right)\end{array}$} & \multicolumn{5}{|c}{ Section-1 } & \multicolumn{2}{c}{ Section-2 } & \multicolumn{2}{c}{ Section-3 } \\
\cline { 2 - 7 } & test & theory & test & theory & test & theory \\
\cline { 2 - 7 } & 8.67 & 7.82 & 9.23 & 7.82 & 8.21 & 6.74 \\
\hline 5 & 11.89 & 7.82 & 11.43 & 7.82 & 7.70 & 6.74 \\
\hline-5 & 15.30 & 7.82 & 17.57 & 7.82 & 13.07 & 6.74 \\
\hline-10 & 19.40 & 7.82 & 22.13 & 7.82 & 14.79 & 6.74 \\
\hline
\end{tabular}

The difference between frost pressure and Marston's theory is the approximated earth pressure induced by the soil freezing.

From the monitoring results of frost heaving magnitude with respect to the freezing depth shown in Fig. 6, the supply water into the soil ground is greatly influenced by comparing frost heaving magnitude between test Section-1 and Section-2, because the soil composition test Section-1 and test Section-2 are the identically same as a decomposed granite soil overlying sandy soil. The composition of test Section-3 consists of silty clayey soil which contains a large quantity of water.

\section{CONCLUSIONS}

A large scale field tests for water supply pipeline were conducted to evaluate the behavior of WSP during the winter season. Several influence factors such as types of soil, moisture content of soil, materials of WSP and freezing temperature were considered throughout the field conditions. Based on the field test results, several conclusions are drawn as follows,

1. The WSP which is buried with the freezing depth, it takes earth pressure due to overburden soil and also freezing pressure induced by the freezing soil.

2. The compression force was pressured on the upper part of WSP. Meanwhile, the tensile force applied on the lower part of WSP.

3. The magnitude of earth pressure on the WSP at the temperature $0^{\circ} \mathrm{C}$ increase about 2.4 time greater than that of unfrozen ground when it is buried below freezing depth. If the soil temperature goes down to $-10^{\circ} \mathrm{C}$, the earth pressure on the WSP gives 3.7 times greater than that of unfrozen case.

4. It is found out that the freezing depth in Songdo area was about $45 \mathrm{~cm}$ with the coldest temperature of $-12^{\circ} \mathrm{C}$ and also the period of temperature below $0^{\circ} \mathrm{C}$ was lasted 81 days during the season 2012-2013.
5. In the design of WSP for installation in the cold region, evaluation of earth pressure by using Marston's theory is not safe enough. Therefore, the buried location of WSP must avoid the infiltration of water with proper drainage system.

\section{ACKNOWLEDGEMENTS}

This work was supported by the Ministry of Land, Transport and Maritime Affairs (MOLTM) grant funded by the Korea government (NTRM) (No. 12CCTI-C058191-02-000000) and "The Design Standard Specifications Evaluation for Frozen Rupture Protection of Water Supply Line”, which is the key development project of the Research Development Project for Construction Transportation Technology for 2011-2014.

\section{REFERENCES}

1) American Society for Testing and Materials (2007): Standard Test Methods for Frost Heave and Thaw Weakening Susceptibility of Soils, Annual Book of ASTM Standard Designation, D 5918-06, 401-412.

2) Marston A. and Anderson, A. (1913): The Theory of Loads on Pipes in Ditches and Test of Cement and Clay Drain tile and Sewer Pipe, Iowa Engineering, Experiment Station Bull., Iowa College Ames. Iowa No. 31, 181.

3) Ministry of Environment (2011): Statics of Water Supply Pipelines, Korea, 1209-1272 (in Korean).

4) Ministry of Land, Transport and Maritime Affairs (2014): The Design Standard Specifications Evaluation for Frozen Rupture Protection of Water Supply Line, No. 12CCTI-C058191-02-000000 (in Korean).

5) Park, S.W, Do, J.N, Jeong, J.J. and Chon, H.S. (2008): Vertical earth pressure on buried pipes in ditches due to fills, Korean Geotechnical Society, 9(1), 11-16 (in Korean).

6) Ryu, B.H. (2013): Deformation Factors and Behavior Characteristics of the Water Supply Pipeline During Ground Freezing, Ph. D. thesis, Incheon National University, Korea (in Korean).

7) Spangler, M. and Handy, R. (1982): Soil Engineering $4^{\text {th }}$ ed., Harper and Row, 727-740. 